\title{
Prevalence of Human Immunodeficiency Virus (HIV) among Tuberculosis Patients Attending Directly Observed Treatment Short-Course (DOTS) Clinic in Port Harcourt, Nigeria
}

\author{
Smart Enoch Amala ${ }^{1}$, Constancy Prisca Aleru ${ }^{2}$ \\ ${ }^{1,2}$ Department of Medical Laboratory Science, Rivers State University of Science and Technology, Nkpolu-Oroworukkwo, Port Harcourt, \\ Nigeria
}

\begin{abstract}
The prevalence of human immunodeficiency virus (HIV) among tuberculosis (TB) patients attending directly observed treatment short-course (DOTS) clinic in University of Port Harcourt Teaching Hospital (UPTH), was investigated. Out of 152 blood samples collected from TB positive patients, 74 had HIV infection. Among the 74 HIV/TB positive patients, 42 (27.6\%) were females while 32 (21.1\%) were males. As regards age, age group 31-40yrs recorded the highest prevalence of (17.11 \%) compared to other age groups. Followed by age groups 21-3yrs and 41-50yrs, $13.16 \%$ and $7.24 \%$, respectively. In addition, the highest number of HIV positive TB male patients was recorded among 31-40yrs 12 (7.89\%); followed by age group 21-30yrs 8 (5.26\%) while there was no HIV positive TB male patient among age group 61-70yrs (0). However, among the TB positive female patients, the highest was recorded among age group 31-40yrs 14 (9.21\%); followed by age group 21-30yrs 12 (7.89\%), while age group 61-70yrs had the least number of HIV positive TB patients $1(0.66 \%)$. More so, in line with this study, the overall prevalence rate of HIV/TB co-infection was $48.7 \%$. This therefore shows that the prevalence of the co-infection is high despite measures taken in the previous years to combat it. Furthermore, as regards the increase in the prevalence rate of the co-infection, factors such as smoking, indulgence in alcohol, sexually active patients as well as having multiple sex partners were observed to predispose patient and increase the likelihood of co-infection with $T B / H I V$, thereby increase the prevalence rate.
\end{abstract}

Keywords: Prevalence; HIV; Tuberculosis; co-infection

\section{Introduction}

Tuberculosis (TB) is one of the major public health problems worldwide with an estimated one third of the world's population being affected by the agent, Mycobacterium tuberculosis (Kwaru et al., 2008). The disease has existed among humans since ancient times and had been reported as the most common significant and infective aerosolized respiratory infection with Mycobacterium tuberculosis, the causative agent of TB (Thomas, 2006). In 2005, WHO reported that an estimated seven million new cases occur every year, which results in 2-3 deaths regardless of the disease being curable and preventable with vaccine and effective treatment regimens.

It had been established that there is a link between tuberculosis and Human Immunodeficiency Virus/Acquired Immune Deficiency Syndrome (HIV/AIDS). This is because the findings of different studies had shown similar conclusions of rise in prevalence and these studies were conducted both in the developed and developing nations (Elliot et al., 1990; WHO, 2005). In African countries, TB/HIV co-infection was estimated from 19.3 - 43.17\%, Asian countries 9.92 - 24.46\%, European countries 13.82 26.39\%, Latin America $19.28-30.8 \%$ and USA 10.44 19.24\% respectively (Gao et al., 2010). HIV and Tuberculosis co-infection present diagnostic and therapeutic challenges on public health care system. They exert synergistic effects in accelerating the deterioration of the functions and responses of the host's immune system. In addition, HIV has paved way for the resurgence of TB disease and as a result, it is noted that the disease is the most powerful risk factor of $M$. tuberculosis infection (Yusuph $e t$ al., 2005; Van Altena et al., 2007).

More so, as a result of a weakened immune system in HIV patients, they are highly vulnerable to TB; then the disease turns to be the number one killer of the patients with TB, it was also noted that HIV infection presents a major challenge to control of TB globally (WHO, 2O12). According to the estimation by WHO in 2011, 13\% of the 8.7 million people living with TB were HIV positive.

Worldwide about 14 million people are co-infected with $M$. tuberculosis and HIV worldwide, out of which $70 \%$ live in Sub-Sahara Africa. In accordance with the report, in 2007, WHO estimated that there were at least 1.37 million cases of HIV/positive TB or nearly $15 \%$ of the total incident cases. As at early 2009, Infectious Disease Society of America (IDSA) reported that the TB/HIV co-infection crisis is twice bigger than it had been reported TB is a leading killer among HIV infected individual, at least one in four deaths among people living with TB is associated with HIV co-infection (Getahun et al., 2010 , WHO, 2012). In 2010, more than 13 million people were reported to be TB/HIV co-infected worldwide, of which, about $70 \%$ live in sub-Sahara Africa (Papathakis and Piwoz, 2010).

In 2012, the United States Embassy in Nigeria reported that the prevalence of HIV/TB co-infection increased from $2.2 \%$ to $19.1 \%$ and to $25 \%$ in 1991, 2001, and 2010, respectively. In other words, this means that the situation of HIV among TB patients in Nigeria is HIV-driven. HIV presents a major challenge to the control of tuberculosis 


\section{International Journal of Science and Research (IJSR) \\ ISSN (Online): 2319-7064 \\ Index Copernicus Value (2013): 6.14 | Impact Factor (2015): 6.391}

globally (WHO, 2012). Also, according to United States Agency for International Development (USAID - 2012), Nigeria has the largest number of people living with the coinfection and accounts for $10 \%$ of the global HIV burden with approximately 215, 000 HIV/AIDS related death in 2010. For instance, the co-infection rate ranges from $5.91 \%$ in the Niger Delta region, $10.5 \%$ in Kano, $18.4 \%$ in Lagos, $19.8 \%$ in Benin city and 40 \% in Ilorin (Salami et al., 2006; Okoror et al., 2008; Iliyan et al., 2009; Onubogu et al., 2010; Nwabuko et al., 2012; Okoh et al., 2012). A vicious cycie is formed, HIV fuels TB and TB fuels more TB; as a result cases in Africa is rising by $4 \%$ yeary. TB is always fatal in HIV patients if not diagnosed and treated early.

Even if previous studies have shown that there was a high prevalence of HIV in TB patients, there is need for current documented study from Port Harcourt, Rivers State, Nigeria to ascertain whether there is still continuous increase or decline in the prevalence rate. Hence, this present study is aimed at establishing current prevalence of HIV infection in TB patients attending directly observed treatment shortcourse (dots) clinic in the University of Port Harcourt Teaching Hospital, Rivers State.

\section{Materials and methods}

\section{Study Area}

The study was conducted among TB patients attending Directly Observed Therapy Short-course (DOTS) at the University of Port Harcourt Teaching Hospital (UPTH), Port Harcourt, between May and July 2014. A tertiary health centre along the East-West Road in Chioba, Obio-Akpo Local Government Area, Rivers State, Nigeria. The hospital offers services to the people of Rivers State and other neighbouring states.

\section{Ethical Consideration}

Oral informed consent was obtained from the patients prior to enrolment. For those below 18 years of age, permission was sought from their parents/guardians.

\section{Subjects}

A total of 152 patients who were attending the DOTS clinic of University of Port Harcourt Teaching Hospital (UPTH) presented themselves to be screened for HIV. The subjects were between less than 1 year and 70 years.

\section{Sample Collection And Preparation}

Ethanol $70 \%$ was used clean the site of collection and two millilitres ( $2 \mathrm{ml}$ ) of blood was collected by venipuncture into a plain sample container; but for the children blood was collected by capillary. The blood were allowed to clot. Disposable plastic pipettes were used to separate the serum from the red cells.

\section{Laboratory Analyses}

The samples were analysed using HIV determine kits: manufactured by Abott Laboratories, Matsuhidai, Japan.

\section{Principle of the Test}

Determine HIV type 1 and 2 is an immunochromatographic test for the qualitative detection of antibodies to HIV type 1. The HIV type 2 samples were added to the sample pad. As the sample migrates through the solid phase to the immobilized recombinant antigens and synthetic peptides at the patient window site, if the antibodies to HIV type 1 and/or HIV type 2 are present in the sample, the antibodies form a red line at the patient's window site.

If antibodies to the HIV type 1 and 2 are absent, the antigen selenium colloid flows past the patient window and no red line is formed at the patient's window site.

\section{Procedure}

The procedures for the test were based on recommendation of the manufacturers. The steps are as follows:

The ABBOT determine HIV type 1 and 2 test kit was brought to room temperature and the protective foil cover was removed from each strip before use, the test sera collected were also brought to room temperature. Using a micropipette, $50 \mu \mathrm{l}$ of each test serum sample was introduced and left to stand for 5-15 minutes at room temperature. The results were read visually.

\section{Interpretation of Results}

A positive result is represented by the appearance of a two (2) red bars in control in both the control window labelled "control" and the patient's window labelled "patients" of the strip. Any visible red colour in the patient's window should be interpreted as positive.

In a negative result, one of the red bars would appear only at the control window of the strip labelled "control" and no red bar appears in the patient's window of the strip labelled "patient". However, a result is invalid when no red bar appears in the control window of the strip and even if a red bar appears in the patient's window of the strip, the result was invalid and was repeated.

\section{Result}

\begin{tabular}{|c|c|c|}
\hline $\begin{array}{c}\text { Number of subjects } \\
\text { examined }\end{array}$ & $\begin{array}{c}\text { Number of } \\
\text { positive subjects }\end{array}$ & $\begin{array}{c}\text { Prevalence } \\
(\%)\end{array}$ \\
\hline 152 & 74 & $48.7 \%$ \\
\hline
\end{tabular}

Out of one hundred and fifty two (152) TB patients screened for HIV, seventy four (74) tested positive to HIV. Therefore, the overall prevalence of HIV/TB co-infection in this study population was $48.6 \%$ as shown on Table 3.1: Overall prevalence of HIV/TB co-infection among the study population

3.2. As illustrated in Figure 1, the percentage rate of HIV infection among TB patients was higher among the females than in males by $53.8 \%$ and $43.2 \%$, respectively. 


\section{International Journal of Science and Research (IJSR) \\ ISSN (Online): 2319-7064 \\ Index Copernicus Value (2013): 6.14 | Impact Factor (2015): 6.391}

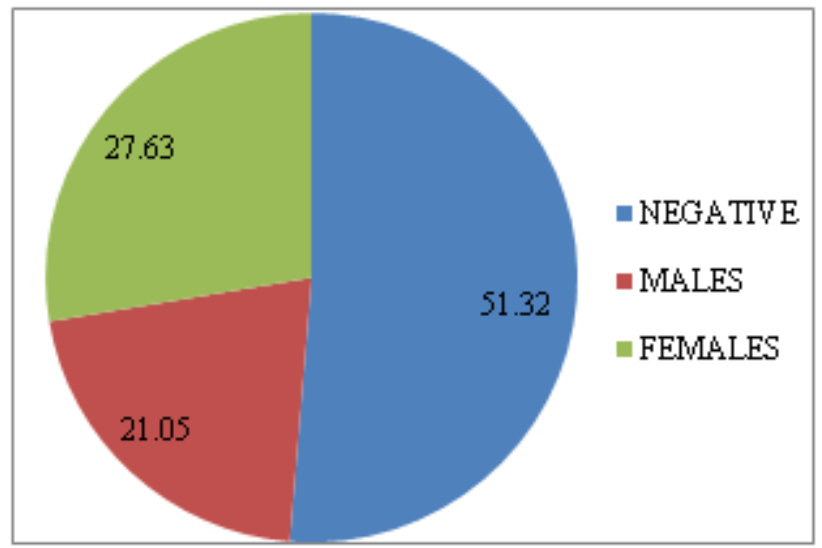

3.3 According to Figure 2, the prevalence of HIV/TB coinfection also varied with age of the patients. It was highest among age group 31-40yrs 26(17.11\%) out of 44 TB/HIV patients examined, followed by those aged 21-30yrs $20(13.16 \%)$ out of 36 TB patients examined, age group 4150 yrs $11(7.24 \%)$ out of 21 TB patients examined, age group $<1-10 y$ rs $10(6.58 \%)$ out of 20 TB patients examined, age group 51-60yrs 2(1.32 \%) out of 8 TB patients examined, age group 11-20yrs $4(2.63 \%)$ out of 17 TB patients examined and the least, which was among age group 6170yrs $1(0.66 \%) 6$ TB patients examined.

Figure 1: Percentage of HIV infection among TB patients with respect to gender

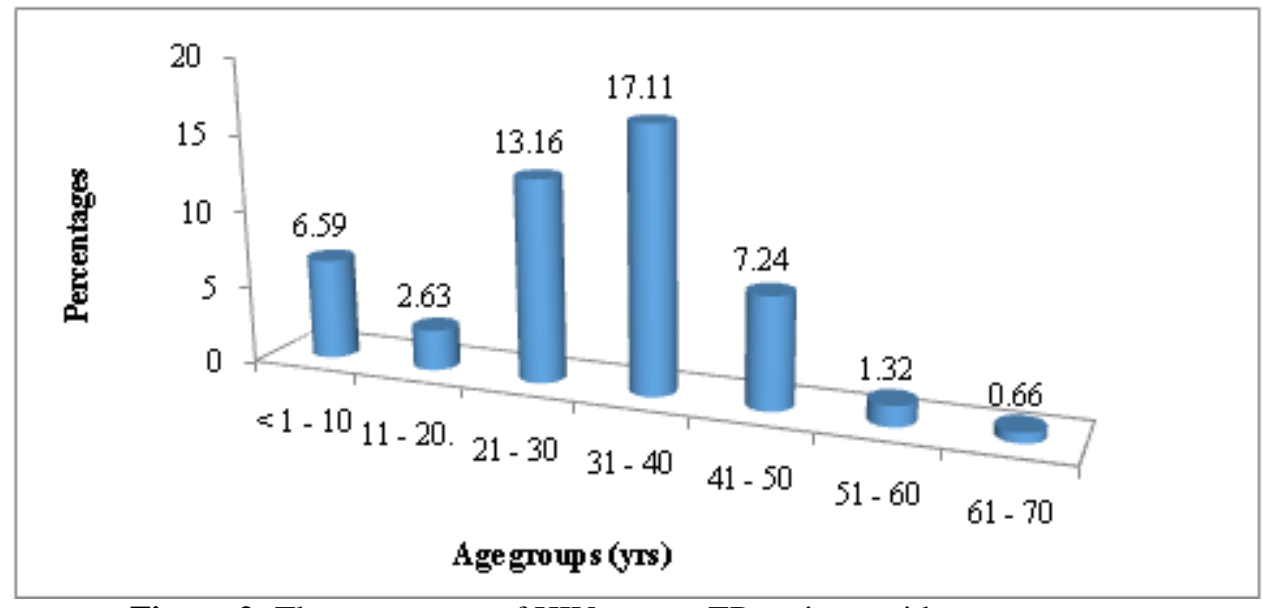

Figure 2: The percentage of HIV among TB patients with respect to age

3.4 As shown in Figure 2, the prevalence of HIV/TB coinfection among the age groups as regards gender shows that the co-infection is more among the females than in males among the age groups 21- 40 yrs, the percentage prevalence is slightly higher in males.

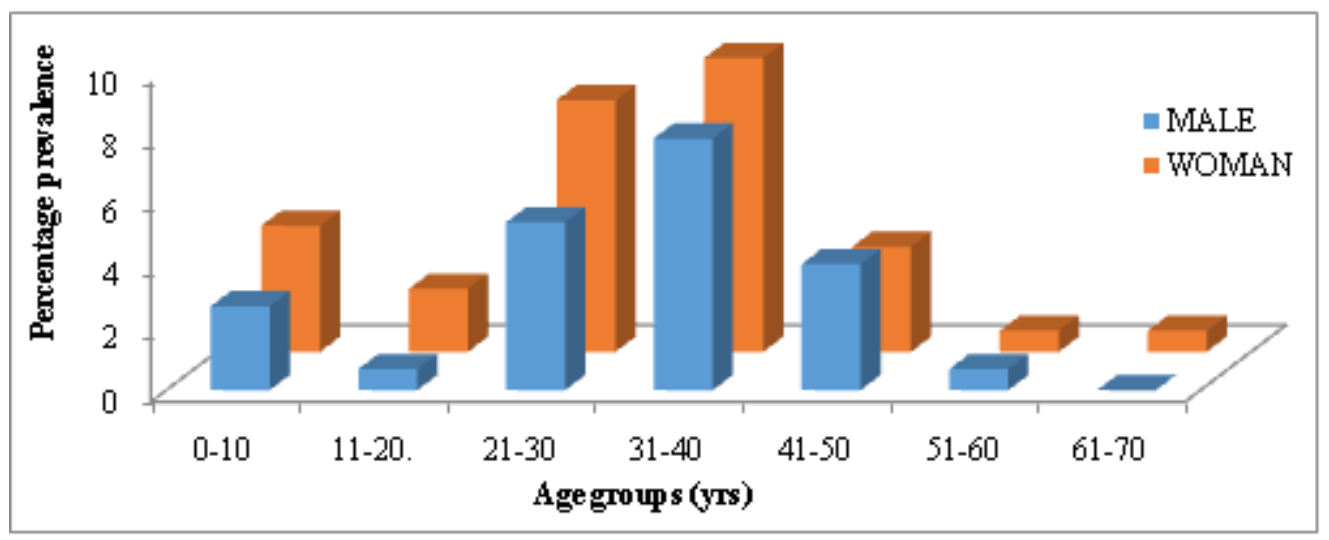

Figure 3: A comparison between the male and female HIV positive TB patients

\section{Discussion}

From the present study, the overall percentage prevalence rate of HIV/TB co-infection is $48.7 \%$ and this is similar to the findings by Adjei and his colleagues. In their studies, the prevalence of HIV/TB co-infection was $46.2 \%$ (Adjei et al., 2006). However, a previous study carried out in Tanzania in 2005 was not as high as the prevalence rate reported by Adjei and his co-researchers. This may be as a result of differences in the study areas as these three studies, including the present one, were done in different countries in Africa (Ghana, Tanzania and Nigeria). From the results of some previous studies, which were conducted in Nigeria, the overall percentage prevalence showed that HIV/TB coinfection is on the increase because the findings of 2004 and 2013 are lower than the findings of the present study (37.5 $\%, 32.2 \%$ and $48.7 \%$ ), respectively (Uche and Alozie, 2004; Ahmed et al., 2013). This might not be unconnected to the fact that some Nigerians are reluctant to go for HIV and TB screening, unless they have job opportunity that 


\section{International Journal of Science and Research (IJSR) \\ ISSN (Online): 2319-7064 \\ Index Copernicus Value (2013): 6.14 | Impact Factor (2015): 6.391}

require certificate of medical fitness, (present health status) prior to the offer of appointment, or when there are obvious signs and symptoms of disease.

Reports from different states in Nigeria are as well on the increase. For instance, studies that were carried out in Irrua, Nguru and Benue State, showed the prevalence rates of 10.8 \%, $23.6 \%$ and $35.1 \%$, respectively (Nwobu, et al., 2004; Yusuph et al., 2005; Odaibo et al., 2006). In Sub Saharan Africa, the percentage prevalence from some countries were also on the increase; Botswana 79\%, Ethiopia 29\%, Kenya $51 \%$, Mozambique 41\%, South Africa 60\% and Uganda $24 \%$ respectively. It was estimated that in some Sub Saharan African countries, 75\% TB patients are infected with HIV/AIDS and TB/HIV kills more than 450,000 people in Africa each year (UNAIDS, 2003).

Out of the 74 (48.6\%) positive cases of HIV/TB coinfection in this study, it was noted that 42 (27.63\%) were females while 32 (21.05\%) were males. This result, clearly shows that the females are more prone to HIV/TB coinfection than the males, which may be because more women, including the teenagers are involved in social activities as well as interacting with each other than the males. This is in accordance with the studies carried out in Europe, North America and Uganda, where the prevalence rates were higher among the females than in males (Getahun et al., 2010, Ahmed et al., 2013, Gao et al., 2013). However, statistically, using chi-square $\mathrm{p}<0.05$, there was no significant difference in the prevalence rate of HIV/TB coinfection among males and females.

The present study showed that age group 31-40yrs had the highest prevalence rate in both the males and the females, which is $17.11 \%$. Followed by age groups $21-30 y r s$ and $41-$ 50yrs (13.16\% and $7.24 \%)$, respectively; whereas, the least prevalence rate was found among age group 61-70yr (0.66 $\%)$. Also, as regards age groups and gender, there was no HIV positive TB patient recorded among the males in the later age group however, among the females, HIV positive TB female patient was recorded as 1 (0.66\%). Generally, based on the results of this study, the high prevalence rates observed among age groups 31-40yrs, 21-30yrs and 41$50 y r s$, might be because the people that fall within these age groups that were sexually active. Most of them are unmarried and they may have multiple sex partners or indulge in homosexual practices. Women within these age groups are more associated in commercial sex working, addiction to intravenous drug use (sharing drug needles), which makes them more vulnerable. More so, the higher prevalence rate observed among age group <1-10yrs compared to the age group 11-20yrs could possibly be due to maternal HIV transfer in pregnancy, coupled with diminishing immunity experienced by children; while struggling to build up their immunity and fetus may contract the virus through the umbilical cord and/or through the birth canal during childbirth.

\section{Conclusion}

The overall prevalence rate of the study is quite alarming and this shows that HIV/TB co-infection still remains a challenge to the society in spite of the measures taken in the past to combat or reduce its incidence. Therefore, more serious measures should be taken by the relevant authorities to battle this menace. This may need collaborative efforts with government and relevant authorities.

Finally, it is therefore recommended that HIV and TB screening conducted concomitantly for patients positive for either disease.

\section{References}

[1] Ahmed, W.A., Prajapati, R.K., and Bilkisu, B.Y., (2013). Incidence of tuberculosis among human immunodeficiency virus (HIV) patients attending General Hospital Bajoga. Journal of Pharmacy and Biological Sciences, 7, 69-72.

[2] Elliot, A-M., Luo, N. and Tembo, G. (1996). Impact of HIV on tuberculosis in Zambia: a cross-sectional study. Manson's Tropical Disease, 96, 301-412.

[3] Gao, J., Zieng, P. And Fu, H.(2013). Prevalence of HIV/TB co-infection in countries except China. A systematic review and meta analysis. PLOS ONE 8(5), e64915.

[4] Getuhun, N., Gunneberg, C.Granich, B. and Nunn, P. (2010). HIV infection associated tuberculosis, the epidemic and the response. Clinical Infectious Diseases, 50(3), 201-207.

[5] Ilyasu, z. and Babashani, M. (2009). Prevalence and predictors of tuberculosis co-infection among HIV seropositive patients attending the amino Kano teaching hospital, Northern Nigeria. Journal of Epidemiology, 19, 81-87.

[6] Infectious Disease Society of America, (2009). Alarming new data shows TB-HIV co-infection a bigger threat. $\quad$ Retrieved from: http://www.idsociety.Org_HIVMA_adult_oi [Retrieved February 6 2016].

[7] Kwaru, A.H., Muhammad, A.B., Nwokedi, E.E., Umar, A. and Magashi, M.A. (2008). Prevalence of human immunodeficiency virus among tuberculosis patients in Kano, Nigeria. Africa Journal Online, 6, 1-2.

[8] Nwabuko, C.O., Ejele, O.A., Chuku, A., Nnonli, M.A. and Chunwunonye, I.I. (2012). Prevalence of tuberculosis HIV co-infection and relationship between tuberculosis and CD4+ count/ESR in HIV patients in Niger Delta Region of Nigeria. Journals of Dental and Medical Science, 2, 01-04.

[9] Nwobu, G.O., Okodua, M.A., and Tatfeng, Y.M., (2004). Comparative study of HIV associated pulmonary tuberculosis in chest clinic from two religions of Edo State, Nigeria. Online Journal of Health Allied Sciences, Accessed from: http://www.ojhas.org/issue11/2004-3-htm [Accessed February 2 2016].

[10] Odaibo, G.N., Gboun, M.F., Ekanem, E.E., Gwargo, S.N., Salui, I., Egbewunmi, S.A., Abebe, E.A., and Olaleye, D.O., (2006). HIV infection among patients with PTB in Nigeria. African Journal of Medicine and Medical Sciences, 35, 93-98.

[11] Okoh, A. and Omuemu. (2012). Prevalence of HIV/AIDS and TB co-infection among patients in Benin city, Nigeria. Geneva, Health Forum, 12. 
[12] Okoror, L. E., Esumeh, F.I., Umolu, P.I., Eraigbe, R., Akpe, H-A., Obiazi, F.A. andImahia, I. (2008). Prevalence of HIV in suspected patients attending clinics in Benin city, Nigeria. The Open Tropical Medicine Journal, 1, 8-12.

[13] Onubogu, C.C., Kunle-Ope, C.N., Onyejepu, N., Nwokoye, N.N., Raheen, T.Y., Igbasi,U.T.,Tochukwu, N.E., Omoleye, R. M., Ejezie, C.O., Musa, A.Z., Odunukwe, N.N., Onwujekwe, D.I. and Idigbe, E.O. (2010). Prevalence of tuberculosis and HIV co-infection among patients with broncho pulmonary disorders in Lagos. African Journal of Microbiology Research, 4, 1904-2010.

[14] Papathakis, P. and Piwoz, E. (2010). "Nutrition and tuberculosis, a review of the literature and consideration for TB control programs". Retrieved from: http://wwwworks.bepress.com/ppatha/2/[Retrieved February 6 2016].

[15] Salami, A.K. and Katibi, I.A. (2006). HIV-associated tuberailosis: pattern and trend in the University of Ilorin Teaching Hospital. African Journal of Medical Science, 35, 437-460.

[16] Thomas, M.D. (2008). The history of tuberculosis. Respiratory Medicine, 100, 1862-1870.

[17]UNAIDS, (2003). Technical guidance or further documents on the management of TB/HIV. Retrieved from

http://www.data.unaids.org/ungass_report_2003_en [Retrieved 28 March, 2006].

[18] United States Agency for International Development, (2012). Infections Disease. TB/HIV, MDR-TB, and other challenges.

[19] United States Embassy Nigeria, (2012). Nigeria tuberculosis factsheet. Retrieved from: http://www.nigeria.us embassy [Retrieved February 6 2016].

[20] World Health Organization, (2005). Global tuberculosis control surveillance, planning and financing: WHO/MTM/TB/2005, Geneva, 369.

[21] World Health Organization, (2010). Priority research questions for TB/HIV in HIV prevalence and resources limited setting. Geveva WHO press.

[22] World Health Organization, (2012). WHO policy on collaborative TB/HIV activities guideline for national programmes and other stakeholders. Geneva WHO press.

[23] Yusuf, H., Lialani, S.B. and Ahedjo, A. (2005). Prevalence of HIV in patients in Nigeria North Nigeria. Medical Journals, 8, 65-67. 